\title{
Erratum to: Preschool morphological training produces long-term improvements in reading comprehension
}

\author{
Solveig-Alma Halaas Lyster ${ }^{1}$ • Arne Ola Lervåg ${ }^{1}$ • \\ Charles Hulme ${ }^{1,2}$
}

\section{Erratum to: Read Writ \\ DOI 10.1007/s11145-016-9636-x}

In the original publication of the article, the name of the second author was spelled incorrectly. The correct author name is given in this erratum.

The online version of the original article can be found under doi:10.1007/s11145-016-9636-x.

$₫$ Solveig-Alma Halaas Lyster sol.lyster@isp.uio.no

1 University of Oslo, Oslo, Norway

2 University College London, London, UK 